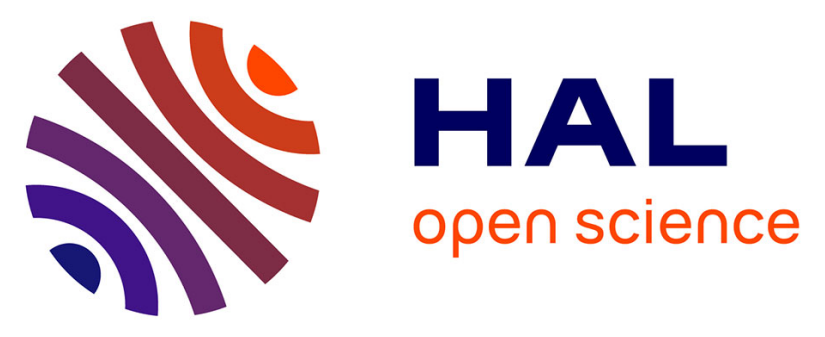

\title{
Powder processing methodology for fabrication of Copper/Graphite composite materials with enhanced thermal properties
}

\author{
Adrien Morvan, Jean-Luc Grosseau-Poussard, Nathalie Caillault, Florence \\ Delange, Sophie Roure, Pascal Lepretre, Jean-François Silvain
}

\section{To cite this version:}

Adrien Morvan, Jean-Luc Grosseau-Poussard, Nathalie Caillault, Florence Delange, Sophie Roure, et al.. Powder processing methodology for fabrication of Copper/Graphite composite materials with enhanced thermal properties. Composites Part A: Applied Science and Manufacturing, 2019, 124, pp.105474. 10.1016/j.compositesa.2019.105474 . hal-02158663

\section{HAL Id: hal-02158663 https://hal.science/hal-02158663}

Submitted on 1 Oct 2020

HAL is a multi-disciplinary open access archive for the deposit and dissemination of scientific research documents, whether they are published or not. The documents may come from teaching and research institutions in France or abroad, or from public or private research centers.
L'archive ouverte pluridisciplinaire HAL, est destinée au dépôt et à la diffusion de documents scientifiques de niveau recherche, publiés ou non, émanant des établissements d'enseignement et de recherche français ou étrangers, des laboratoires publics ou privés. 


\section{Powder processing methodology for fabrication of}

\section{Copper/Graphite composites with enhanced thermal}

\section{properties}

Adrien Morvan $^{\mathrm{a}, \mathrm{b}}$, Jean-Luc Grosseau-Poussard ${ }^{\mathrm{c}}$, Nathalie Caillault Florence Delange ${ }^{b}$, Sophie Roure ${ }^{d}$, Pascal Lepretre ${ }^{d}$ and Jean-François Silvain ${ }^{\mathrm{a}, \mathrm{e}^{*}}$

aUMR 5026, Institut de Chimie de la Matière Condensée de Bordeaux (ICMCB), 87 Avenue du Docteur Albert Schweitzer, 33600 Pessac, France

${ }^{\text {bS }}$ chneider Electric SAS, 38 TECl, 38000 Grenoble, France

'LaSIE UMR-CNRS 7356, Pole Science et Technologie, Université de La Rochelle, Av. M. Crépeau, 17042 La Rochelle Cedex, France

'Schneider Electric SAS, 38 EQI, 38320 Eybens France

${ }^{e}$ Department of Electrical and Computer Engineering, University of Nebraska-Lincoln, Lincoln, NE 68588-0511, USA

*Corresponding author: jean-francois.silvain@icmcb.cnrs.fr; Phone: +33 (0)540008437

\section{Graphical abstract:}

Grf powder thermal treatment under $\mathrm{Ar} / \mathrm{H}_{2}(\mathbf{5 \%})$

Lower amount of $\mathrm{sp}^{3}$ $\mathrm{C} /$ defects in the $\mathrm{C}$ lattice

Hot pressing

Anisotropic dense $\mathrm{Cu} / \mathrm{Grf}$ vol.\% composites Improved thermal conductivity in Grf in-plane even at low vol. \% of Grf
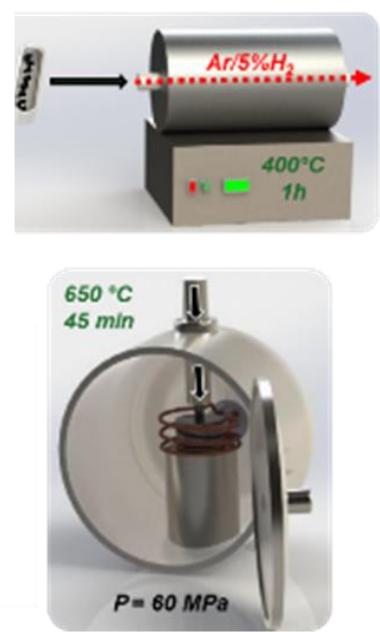

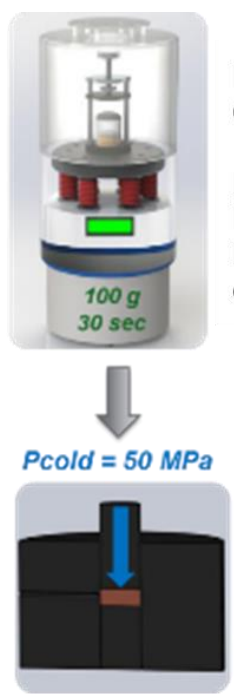

Resonant acoustic mixing of Cu/Grf powders

Faster mixing

Fewer local heat generated Elimination of Grf edges defects

Cold pressure of mixed Cu/Grf powders

Alignement of the Carbon reinforcement in a plane perpendicular to the pressing direction (Grf in-plane) 


\section{Abstract:}

This study focuses on the powder processing methodology (PPM) for the fabrication of metal matrix composite using Graphite flakes (Grf) reinforced Copper (Cu). The manufacturing route involved 1) a reductive treatment of Grf powder to purify and increase its quality, 2) the mixing of the $\mathrm{Cu}$ and the $\mathrm{Grf}(0$ to 40 vol.\%) powders with a fast and efficient resonant acoustic (RA) mixer, and finally 3) the cold and hot-pressing of composite powders. Comparison of PPM is made with literature and a usual method used in our laboratory. The quality of Grf after different steps was analyzed by Raman spectroscopy and phase compositions and microstructure of the composite materials were analyzed by XRD and SEM, respectively. It was shown that this new PPM demonstrated better composite structural and thermal properties even at low volume fraction of Grf with a maximum of $630 \mathrm{~W} \cdot \mathrm{m}^{-1} \cdot \mathrm{K}^{-1}$ obtained with 40 vol.\% of Grf at $70{ }^{\circ} \mathrm{C}$. This was possible thanks to our new PPM which allows getting lower defects in the Carbon lattice of Grf and oxygen content in the final composite materials.

\section{Keywords:}

A - Metal-matrix composites (MMCs); B - Thermal properties; E - Powder processing methodology

\section{Introduction}

Recently, the adaptive physical properties of Carbon/Metal Matrix Composites (MMCs) is receiving increasing attention. Addition of Carbon (C) such as Graphite flakes (Grf) to metallic matrix such as Copper $(\mathrm{Cu})$ reduces its density and increases its thermal conductivity (TC) measured parallelly to the basal plane of Grf.

The fabrication of such composite materials is usually carried out by powders metallurgy process in two main steps: powders mixing and consolidation via sintering technique. In most cases, homogenization of metal and reinforcement powders was obtained after mixing by mechanical [1] [2] [3] or wet mixing [4]. These processes are long or/and induce degradation of reinforcements by chemical contamination, plastic deformation or by local overheating. Analyses performed by Raman spectroscopy on Grf, obtained after ball-milling, have 
demonstrated that the structure of Grf was damaged as the $\mathrm{I}_{D} / \mathrm{I}_{G}$ ratio increased after mixing step and densification [1].

In this work, a new powder processing methodology (PPM) was investigated to avoid creation of defects in Grf and therefore to improve the thermal properties of Grf and consequently the thermal properties of the $\mathrm{Cu} / \mathrm{Grf}$ composite materials. We have investigated how 1 ) a reductive treatment of the Grf, prior to mixing step, tend to reduce the oxygenated $\mathrm{sp}^{3}-\mathrm{C}$ content and 2) how a new and fastest mixing method homogeneously disperse the Grf inside the Cu matrix without generated any degradations of the mixed powders. This mixing method, which is based on resonant acoustic (RA) mixing, is already used by pharmaceutical industries to mix powder bled. This non-contact mixing technology helps to improve quality at the edges of Grf thanks to a multitude of micro-mixing cells throughout the vessel. The effect of this new PPM on the $\mathrm{TC}$ of $\mathrm{Cu} / \mathrm{Grf}$ composite materials is demonstrated and discussed. Comparison of composites TC obtained with conventional 3-dimensional (3D) mixing process has been done. Using this new PPM, TC of the $\mathrm{Cu} / 40$ vol.\% Grf composite material, after consolidation using conventional hot-pressing method, showed in-plane TC up to $630 \mathrm{~W} \cdot \mathrm{m}^{-1} \cdot \mathrm{K}^{-1}$ at $70{ }^{\circ} \mathrm{C}$.

\section{Experimental sections:}

\section{a) Materials}

Cu particles with dendritic shapes (Figure 1) have a $d_{50}$ close to $30 \mu \mathrm{m}$ and are supplied by ECKA $^{\circledR}$ Granules (Germany, $\mathrm{GmbH}$ ). The dendritic powder has been chosen for this study because of its high purity and its dendritic shape which lead to easy grain deformability and therefore high final density. Figure 2 shows SEM micrographs of raw natural Grf with particles mean lateral size close to $500 \mu \mathrm{m}$ and an average thickness of $30 \mu \mathrm{m}$. They are provided by Yanxin-Graphite Co., Ltd. As it was already discussed by Ben Liu et al. [5], Grf particles size could affect the final physical properties (such as TC) of the composite material. Thereby, prior to be used, Grf were sieved to obtain a homogeneous powder lateral size, ranging between 355 and $400 \mu \mathrm{m}$.

b) Reduction of graphite powder 
To perform the heat treatment under reductive atmosphere $\left(\mathrm{Ar} / \mathrm{H}_{2}(5 \%)\right.$ with a flow of 200 $\mathrm{mL} / \mathrm{min}$ ), a certain amount of Grf was placed in an alumina pod and then placed in the center of a tubular furnace. The furnace was heated at $6^{\circ} \mathrm{C} / \mathrm{min}$ to the bearing temperature $\left(200^{\circ} \mathrm{C}\right.$, $400^{\circ} \mathrm{C}$ and $800^{\circ} \mathrm{C}$ ) and then kept for an hour at annealing temperature. The decrease of temperature was obtained by natural cooling of the furnace.

\section{c) Powder mixing}

Composite powders (Cu/Grf) were mixed in a classical 3D mixer (Turbula ${ }^{\circledR}$ Shaker/Mixer Model T2C, Germany) for 120 min at 40 RPM. Another mixing process was evaluated and compared to the 3D mixing, the RAM (Labram, Resodyn, USA). This device was operating at $60 \mathrm{~Hz}$, during 30 seconds with an acceleration of $100 \mathrm{~g}$.

d) Composite materials

Three sets of composite materials were sintered. Set A, Cu/Grf after 3D mixing; Set B after RA mixing and Set $\mathrm{C}, \mathrm{Cu} / \mathrm{Grf}\left(\mathrm{Ar} / \mathrm{H}_{2}(5 \%)\right)$ fabricated after RA mixing with an additional step in the process: reductive treatment of $\mathrm{Grf}$ under $\mathrm{Ar} / \mathrm{H}_{2}(5 \%)$ before mixing. The mixture, with a volume fraction of Grf ranging between 0 to $40 \%$, was cold pressed in a carbon mold of $20 \mathrm{~mm}$ in diameter and then placed in a Thermolab ${ }^{\circledR}$ press. All Sets of powders were heated at $650{ }^{\circ} \mathrm{C}$ using induction system, under a uniaxial compressive stress of $60 \mathrm{MPa}$ for $45 \mathrm{~min}$. The temperature was monitored via a K-type thermocouple located close to the sample.

e) Microstructural and chemical characterizations

The FT-IR spectra was recorded by grinding spectroscopy grade $\mathrm{KBr}$ with Grf using a BRUKER Equinox $55 \mathrm{FT}$-IR spectrometer in the range of 400 to $4000 \mathrm{~cm}^{-1}$ at $4 \mathrm{~cm}^{-1}$ resolution.

Thermogravimetric analysis (TGA) was carried out on Grf using a TA Q600 thermal analyzer (SDT Q600, TA Instrument Co., USA) under a slightly hydrogenated atmosphere $\left(\mathrm{Ar} / \mathrm{H}_{2}(5 \%)\right)$, over a temperature range of $30^{\circ} \mathrm{C}$ to $1000^{\circ} \mathrm{C}$ with a heating rate of $6{ }^{\circ} \mathrm{C} \cdot \mathrm{min}^{-1}$.

A ThermoFisher Scientific K-ALPHA spectrometer was used for surface analysis of Grf with a monochromatized Al Ka source $(\mathrm{h} v=1486.6 \mathrm{eV})$ and a 200 microns spot size. A pressure of $10^{-7} \mathrm{~Pa}$ was reached in the chamber when transferring the samples pressed onto indium foil. The full spectra $(0-1100 \mathrm{eV})$ were obtained with constant pass energy of $200 \mathrm{eV}$ and high- 
resolution spectra at a constant pass energy of $40 \mathrm{eV}$. Charge neutralization was applied during analysis. C1s, O1s high resolution spectra were fitted and quantified using the AVANTAGE software provided by ThermoFisher Scientific (Scofield sensitivity factors used for quantification).

Grf powder X-ray diffraction (XRD) patterns were collected on a PANalitycal X'pert PRO MPD diffractometer in Bragg-Brentano $\theta-\theta$ geometry equipped with a secondary monochromator and X'Celerator multi-strip detector. Each measurement was made with an angular of $2 \theta$ varying between 8 and 80 with a $2 \theta$ step size of $0.017^{\circ}$. The Cu-Ka radiation was generated at $45 \mathrm{KeV}$ and $40 \mathrm{~mA}(\lambda=0.15418 \mathrm{~nm})$. The patterns were analyzed using EVA software (Bruker).

Grf was characterized after each steps of the composite fabrication process by Raman spectroscopy. The Raman analyses were done with a high-resolution Horiba spectrometer equipped with a CCD detector; its precision is equal to $0.1 \mathrm{~cm}^{-1}$. Measurements were taken in a backscattering micro-configuration. The wavelength of the source is at $\lambda=532 \mathrm{~nm}$, whose maximum power is equal to $10 \mathrm{~mW}$. The laser power is chosen between 5 and $10 \mathrm{~mW}$ to avoid local heating of the samples. This power range is sufficient to obtain optimum resolution. All our experiments were performed at room temperature (RT) with a 50x microscope objective (leading to an analyzed surface area close to $1.6 \mu \mathrm{m}^{2}$.) Positions of the selected bands have been calculated using Pseudo-Voigt and Lorentzian single and multipeak fitting (Fityk 0.9.8 curve fitting and data analysis program) after background subtraction.

Prior to SEM analysis and thermal measurements, due to anisotropic microstructure and properties, samples were machined to obtain two pellets $(\varnothing 6 \times 3.5 \mathrm{~mm})$ revealing transverse (out-of-plane) and in-plane directions of Grf (Figure 3). The starting powders and bulk composites (orientation distribution) microstructures was analyzed by Scanning Electron Microscopy (SEM, VEGA II SBH, TESCAN) equipment. To reveal the microstructure, Cu/Grf composites were prepared using mechanical polishing with waterproof abrasive silicon carbide papers and polishing cloth. 
Considering that the composite materials only contain closed porosity (ranging from 0.2 and 2 $\%)$, the relative density of the $\mathrm{Cu} / \mathrm{Grf}$ composites was measured using the Archimedes principle.

Amount of oxygen was measured for pure sintered $\mathrm{Cu}$ and composites $\mathrm{Cu} / \mathrm{Grf}$. Hot extraction analyses were carried out to determine the elements concentration of materials, using EMGA$621 \mathrm{~W}$ oxygen/nitrogen/hydrogen analyzer from Horiba. The estimated values were quantified, after combustion in a chamber furnace, by a thermal conductivity detector (TCD) and a nondispersive infrared sensor (NDIR).

f) Thermal characterization

The thermal diffusivity $\alpha$ of composite materials was measured parallel and perpendicular to the compressive axis with a LFA 457 Nanoflash laser thermal conductivity apparatus (NETZSCH, Germany). The specimen dimensions were $6 \mathrm{~mm} \times 3.5 \mathrm{~mm}$ (diameter $\times$ thickness). A graphite coating layer was applied to the pellet's materials before thermal diffusivity measurements. The measurements were performed from RT to $130^{\circ} \mathrm{C}$.

The specific heat $C_{p}$ of the composite was calculating using equation 1 :

$C_{p}=f_{C u} \cdot C_{p}{ }^{C u}+f_{G r f} \cdot C_{p}$ Grf,

Where $\mathrm{f}_{\mathrm{Cu}}, \mathrm{f}_{\mathrm{Grf}}$ and $\mathrm{C}_{\mathrm{p}}{ }^{\mathrm{Cu}}, \mathrm{C}_{\mathrm{p}}{ }^{\mathrm{Grf}}$ are the weight fractions and the specific heat capacities of $\mathrm{Cu}$ and Grf, respectively. Heat capacity was measured by Differential Scanning Calorimetry from RT to $300^{\circ} \mathrm{C}$ (DSC 8000 Pyris Diamond PerkinElmer). Grf and Cu powders have a heat capacity at $70{ }^{\circ} \mathrm{C}$ of $836 \mathrm{~J}^{\mathrm{kg}}{ }^{-1} \cdot \mathrm{K}^{-1}$ and $393 \mathrm{~J} \cdot \mathrm{kg}^{-1} \cdot \mathrm{K}^{-1}$, respectively.

Thermal conductivity values were obtained by using equation 2 :

$K=\rho_{c} \cdot C_{p} \cdot \alpha$,

where $\mathrm{K}$ is the thermal conductivity $\left(\mathrm{W} \cdot \mathrm{m}^{-1} \cdot \mathrm{K}^{-1}\right)$ of the composite, $\alpha$ is the thermal diffusivity $\left(\mathrm{mm}^{2} \cdot \mathrm{s}^{-1}\right), \rho_{c}\left(\mathrm{~g} \cdot \mathrm{cm}^{-3}\right)$ is the bulk density and $\mathrm{C}_{\mathrm{p}}\left(\mathrm{J} \cdot \mathrm{kg}^{-1} \cdot \mathrm{K}^{-1}\right)$ is the specific heat capacity of the composite. A rule of mixture is applied to determine theoretical density $\rho$ of $\mathrm{Cu} / \mathrm{Grf}$ composites.

\section{Results and discussion}




\section{a) Characterization on Graphite flakes powder}

Figure 4 shows the FTIR spectrum of as-received Grf. Native graphite should present only two main peaks around $1670 \mathrm{~cm}^{-1}$ and $1535 \mathrm{~cm}^{-1}$ attributed to $\mathrm{C}=\mathrm{C}$ aromatic. For our Grf, broad and intense band of $\mathrm{O}-\mathrm{H}$ stretching vibration appears at $3423 \mathrm{~cm}^{-1}$. Around 1448, 1385, 1115, $1016 \mathrm{~cm}^{-1}$ bands corresponding to $\mathrm{O}-\mathrm{H}$ stretching and bending of intercalated water in the sample are also present. Bands of $\mathrm{C}=\mathrm{O}$ and $\mathrm{C}-\mathrm{O}$ from carboxyl groups and $\mathrm{C}-\mathrm{O}-\mathrm{C}$ stretching vibrations are displayed at 1718, 1305, $1080 \mathrm{~cm}^{-1}$. Peaks at $1628 \mathrm{~cm}^{-1}$ and $1579 \mathrm{~cm}^{-1}$, correspond to the stretching of aromatic ring and peaks at 862, 790, 740 and $690 \mathrm{~cm}^{-1}$ represent the aromatic bending respectively. The FT-IR spectrum displays absorption bands at $2980 \mathrm{~cm}^{-1}, 2916 \mathrm{~cm}^{-1}$ and $2850 \mathrm{~cm}^{-1}$ which correspond to the $\mathrm{C}-\mathrm{H}$ symmetrical and asymmetrical stretch vibrations of methyl and methylene. This analysis reveals that Grf showed amounts of oxygen-containing groups endowing the Grf with slightly hydrophilic surface property.

X-Ray Photoelectron Spectroscopy (XPS) survey spectrum of Grf (Figure 5) shows Carbon and Oxygen signals with peak close to $285.1 \mathrm{eV}$ and $531.1 \mathrm{eV}$ corresponding to $\mathrm{C} 1 \mathrm{~s}$ and $\mathrm{O} 1 \mathrm{~s}$ core lines, respectively. High resolution spectrum of $\mathrm{C} 1 \mathrm{~s}$ and $\mathrm{O} 1 \mathrm{~s}$ are shown on Figure 6.a). and b), respectively. Based on the deconvolution of C1s peak, the main peak at $284.5 \mathrm{eV}$ corresponds to the graphite-like $\mathrm{sp}^{2}-\mathrm{C}$, indicating most of the Carbon atoms (70 at.\%) are arranged in a conjugated honeycomb lattice. The other peaks correspond to oxygenated $\mathrm{sp}^{3}$ $\mathrm{C}$ at $285.3,286.2,287.2,288.4$, and $289.5 \mathrm{eV}$, which were attributed to single bonded Carbon and Oxygen atoms such as hydroxyl $(\mathrm{C}-\mathrm{OH})$, epoxy $(\mathrm{C}-\mathrm{O}-\mathrm{C})$, and surface groups such as carbonyl $(\mathrm{C}=\mathrm{O})$ and carboxyl $(\mathrm{COOH})$, respectively. At $291.2 \mathrm{eV}$ and $294.4 \mathrm{eV}$, the shake-up satellite peaks corresponding to $\pi-\pi^{*}$ transition are detected. The analysis of O1s spectra shows that he can be divided in two main peaks at $532.0 \mathrm{eV}(\mathrm{C}-\mathrm{O}-\mathrm{C}+\mathrm{C}-\mathrm{O})$ and $533.4 \mathrm{eV}(\mathrm{O}-$ $\mathrm{C}=\mathrm{O}+\mathrm{C}=\mathrm{O}$ ) corresponding to surface chemisorbed species and confirms $\mathrm{C} 1 \mathrm{~s}$ spectra. $\mathrm{A}$ qualitative study of the different chemical components present in the as-received Grf is presented in Table 1. It was obtained by calculating the integrated area of the deconvoluted 
components in the C1s spectra of Figure 6.a. This material is slightly hydrophilic as it was already found by FT-IR and is prone to react with his environment. A very small amount of Chlorine $(\mathrm{Cl})$ and Sulfur $(\mathrm{S})$ has been detected. The amount of contamination could arise from a surface adhesive as it was mentioned by Ben Liu [5].

Both Raman spectra on Figure 7.a)1 and Figure 7.a)2 from center and edges, respectively, show the four most prominent features in Raman spectra of graphitic materials [6]. The G band appears around $1580 \mathrm{~cm}^{-1}$ and corresponds to $\mathrm{sp}^{2}-\mathrm{C}$ network. The $\mathrm{D}$ band around $1350 \mathrm{~cm}^{-1}$ and $D^{\prime}$ band, around $1620 \mathrm{~cm}^{-1}$, appear when $\mathrm{sp}^{3}-\mathrm{C}$ and $\mathrm{sp}-\mathrm{C}$ are introduced in the C-lattice. Finally, the 2D band, which is the overtone of $D$ band, appears around $2720 \mathrm{~cm}^{-1}$. From Figure 7.a), one can see that more defects are introduced in the C-lattice at the flake edges as bands D and D' are more intense in the spectra 2 than in the spectra 1 (related to the flake center).

b) Effect of reductive treatment on Graphite flakes reinforcement To remove most of the oxygen $\mathrm{sp}^{3}-\mathrm{C}$ species from Grf, a reductive treatment under $\mathrm{Ar} / \mathrm{H}_{2}(5 \%)$ was chosen instead of a chemical treatment [5]. To determine the desorption kinetics under reductive atmosphere, TGA of Grf up to $1000^{\circ} \mathrm{C}$ have been performed. Figure 8 displays the weight loss in three discrete stages. In accordance with the analysis obtained by [7] [8], the weight loss (close to $0.01 \%$ ) in the first stage before $150{ }^{\circ} \mathrm{C}$ is mainly caused by the elimination of physiosorbed and interlamellar water molecules. In the second stage between $150{ }^{\circ} \mathrm{C}$ and $350{ }^{\circ} \mathrm{C}$, significant mass loss (close to $0.59 \%$ ) is primarily attributed to the thermal decomposition of covalently bonded oxygen as by-products of the reduction process. Finally, in the last stage the mass loss (close to $0.6 \%$ ) can be attributed to the removal of more stable Oxygen-containing functional groups and unstable Carbons remaining in the structure. Total amount of Oxygen species desorbed during annealing treatment under $\mathrm{Ar} / \mathrm{H}_{2}(5 \%)$ is close to 1.2 wt.\%. This amount is not negligible as it is known that presence of Oxygen in the final composite could lead to a decrease in TC [9]. Therefore, it is necessary to know which bearing temperatures could allow getting lower amount of oxygenated $\mathrm{sp}^{3}-\mathrm{C}$ without degrading the Clattice of Grf. 
The (002) d-spacing for Grf after several reductive treatments range from $3.377 \AA$ (as-received) to $3.360 \AA$ which compares to $3.356 \AA$ for single crystal graphite (Table 2 ). The slightly larger $\mathrm{d}$-spacing confirms the presence of $\mathrm{sp}^{3}-\mathrm{C}$ species as found, for example, by XPS analysis. Adams [10] reported that TC of Carbon fibers and self-reinforced graphite panel is more correlated with the graphite inter-basal-plane spacing $d_{(002)}$ than with the crystallite size $\left(L_{c}\right.$ or $\left.L_{a}\right)$ calculated from the Scherrer equation. Therefore, small $d_{(002)}$ leads to higher TC of Carbon species. In addition, improved layer plane stacking is consistent with the removal of defects such as vacancies, interstitials and impurities. Thus, the decrease of the $d_{(\mathrm{hkl})}$ of the (002) plane with the thermal treatment can be associated with the increase of the TC of the Grf. According to this correlation between the TC and $d_{(002)}$ spacing found by Adams, the estimated TC of the Grf after reductive treatment at $400{ }^{\circ} \mathrm{C}$ is close to $1100 \mathrm{~W} \cdot \mathrm{m}^{-1} \cdot \mathrm{K}^{-1}$, comparing to about 500 W. $\mathrm{m}^{-1} \cdot \mathrm{K}^{-1}$ for as-received Grf (Erreur ! Source du renvoi introuvable.).

The integrated intensity Raman spectroscopy $A_{D} / A_{G}$ ratio is widely used for characterizing defects in graphitic materials [1][6]. By comparing starting and annealed materials, it is possible to quantify defects introduced to Grf after each step of the process. Results, summarized in Erreur! Source du renvoi introuvable. (average of at least six acquisitions), show that the reduction process helps to decrease the $A_{D} / A_{G}$ ratio especially on Grf edges. The integrated intensity ratio $A_{D} / A_{G}$ for the as-received $G r f$ is 0.13 on the center and increase to 0.36 on the edges (Table 3). This difference of defects is mostly due to broken and folded edges of the flakes as it can be seen on Figure 11 and was already observed by M.A Pimenta on nanographite platelets [6]. Nevertheless, this ratio shows that the as-received Grf possesses quite low defects and should display good thermal properties. With annealing treatment, the decrease of defects amount confirms the restoration of $\pi-\pi$ conjugation through the removal of oxidative debris of Grf. At $200^{\circ} \mathrm{C}$, desorption of water and first carbonyls are taking place but are not yet complete while at $800^{\circ} \mathrm{C}$ the graphitic network is starting to deteriorate du to destruction of $C-C$ bonds. These two assumptions were confirmed by the increase of $A_{D} / A_{G}$ ratio and the decrease of the $W_{G}$ and $W_{2 D}$ positions shift on both localizations. However, the minimum number of defects of the Grf is obtained after reduction treatment at $400{ }^{\circ} \mathrm{C}$. This is 
coherent with XRD measurements where the treatment at $400^{\circ} \mathrm{C}$ was optimal in term of $\mathrm{d}$ spacing and theoretical TC. Therefore, this bearing temperature was chosen for the thermal treatment of Grf as it allows getting the lower defects amount in the C-lattice and should induce higher TC of the final composite materials.

c) Effect of mixing processes on Graphite flakes quality

Powder mixing (Grf and Cu powder) was performed using a RA mixing and compared with more traditional 3D mixing. Summarized results are presented in Erreur! Source du renvoi introuvable. (average of at least four acquisitions). Contrary to ball-milling [1], 3D and RA mixing helps to decrease the number of defects on the edges of the Grf. The increase of the D peak on the center of Grf, with 3D mixing, indicates the additional introduction of defects to the C-lattice as well as a decrease of the crystalline size. It has been demonstrated that it is possible to know the motion of mixing by calculating the Froude number Fr from the equation developed by Mellmann in [11]. For the 3D mixing used in this work, a Fr equal to 0.9 has been calculated for a filling degree of the vessel of 0.5 . This number permits to say that the motion, which is taking place in the mixing vessel, is a cascading type [11]. This flow mode gives rise to high shear mixing between powders as well as between powders and vessel walls. Therefore, frictional heat is created during mixing and increase with mixing time. This overheating, in combination with the 2 hours mixing time, tends to deteriorate the quality of Grf. In contrast, RA mixing time is much smaller (less than a minute). In addition, the use of low frequency $(60 \mathrm{~Hz})$ induces high intensity energy mixing cells which allow a random dispersion of powders throughout the mixing vessel and to reduce frictional heat and processing times [12]. Table 4 shows that both peak positions of $G$ and $2 D$, in $\mathrm{cm}^{-1}$, taken on the edge of Grf, decrease after RA mixing. A. Ferrari et al, have concluded from Raman spectroscopy analyses on graphene/graphite, that a negative shift (in $\mathrm{cm}^{-1}$ ) of both $\mathrm{G}$ and $2 \mathrm{D}$ peak positions correspond to the introduction of tensile strain while a positive shift corresponds to a compressive strain in the C-lattice [13]. From that results, it could be considered that a larger amount of tensile strain has been introduced inside the edges of Grf during the RA 
mixing which could help to decrease amount of broken parts and folded flakes. After uniaxial hot-pressing, the $A_{D} / A_{G}$ ratio increases from of 0.12 to 0.21 on the center of the Grf and from 0.2 to 0.28 on the edges of the Grf. This increase is partly due to uniaxial pressure employed during the densification step which tend to align the Grf, within the copper matrix, in a plane perpendicular to the pressure direction. Also, additional cause to the degradation of Grf can be due to the difference of coefficient of thermal expansion (CTE) between the Grf and the $\mathrm{Cu}$ matrix. Indeed, Cu expands isotropically with a CTE equal to $17.5 \mathrm{ppm} . \mathrm{K}^{-1}$ whereas Graphite expands with a negative CTE $\left(\alpha_{\mathrm{Gr}}=-1.5 \mathrm{ppm} . \mathrm{K}^{-1}\right)$ along their planes and a positive CTE through plane $\left(\alpha_{\mathrm{Gr}}=27.1 \mathrm{ppmK}^{-1}\right)$ perpendicular to the planes. This CTE difference may induce stresses and deformation of the Grf during cooling step of the materials (from densification temperature $\left(650^{\circ} \mathrm{C}\right.$ to $\left.\mathrm{RT}\right)$.

d) Microstructure of the Cu/Grf composite

Figure 12 shows side view micrographs of Cu/Grf composites with 5, 10, 20, 30 and 40 vol.\% of Grf. On these micrographs, light contrast represents the Cu matrix and dark one the Grf reinforcement which exhibits lamellar morphology. During the densification step, the platelet geometry (large length to thickness ratio) of the Carbon reinforcement induces a preferred orientation of Grf in a plane perpendicular to the pressing direction. However, some local disorientations, decreasing with increase of Grf volume fraction from 8,1 ${ }^{\circ}$ for 5 vol. $\%$ Grf and $6,7^{\circ}$ for 40 vol. $\%$ Grf (measured by image analysis on around 1000 Grf with the ImageJ software), with respect to this plane are shown by red circles on Figure 12. These misoriented regions could be explained by the intrinsic morphology of the dendritic $\mathrm{Cu}$ and the contact between Grf. Alignment of flakes above 30 vol.\% becomes better and help to increase the TC in plane perpendicular to the pressing direction [1]. With the increase of Grf content, distances between flakes are shorter and the composite microstructure is dominated by Grf geometry. No differences of microstructure were observed between RA and 3D mixing.

e) Effect of the reductive treatment on the composite density

Figure 13 shows the evolution of the relative density of $\mathrm{Cu} / \mathrm{Grf}$ composite materials with Grf volume content. From that figure, it is clear that relative densities decrease when the volume 
fraction of Grf increases and mostly follow classical rule of mixture. In addition to the porosity, which is inherent to the powder metallurgy route, the decrease in the relative density may be correlated with $\mathrm{Cu}-\mathrm{Grf}$ interfacial voids due to non-chemical affinity between $\mathrm{Cu}$ and $\mathrm{Grf}$ and to the Oxygen functional groups present on Grf surface for Set A and B. For Set C, relative densities are higher on the entire concentration range comparing to Set $A$ and $B$. As demonstrated with TGA (Figure 8) and Raman spectroscopy (Table 4) analysis, the reductive treatment in Set C may induce the shrinkage of Grf. This could be due to the desorption of impurities and interstitial oxygenated groups, and could explain the increase of relative density. However, relative densities were found to be all above $98 \%$ for all set of materials.

f) Effect of the powder process methodology on thermal conductivity Figure 14 summarized in-plane TC and Oxygen content for a $\mathrm{Cu} / 40$ vol.\% Grf composite obtained after different powder processing methodology. Each value is an average of measurements on three different samples and errors are no bigger than marker spot. Our experimental values are compared with $\mathrm{Cu} / \mathrm{Grf}$ materials fabricated using ball milling process in [1]. Several points can be pointed out from this figure:

1. Our experimental TC values are all higher than TC value obtained with ball milling process [1]

2. $T C$ is higher for material mixed with $R A$ mixer $(\operatorname{Set} B)$ than material mixed with $3 D$ mixer (Set A) - this behavior can be attributed to the low amount of defects induce by the RA mixer

3. TC is improved after the annealing treatment under reductive atmosphere of the Grf before densification (Set $\mathrm{C}$ compare to set $\mathrm{B}$ ) - this behavior can be explained by the improvement of theoretical TC value of the Grf

4. The content of oxygen decreases when the $\mathrm{TC}$ of the composite material increases and $\mathrm{Cu} / \mathrm{Grf}$ material after Grf reductive treatment has an oxygen value almost 6 times lower than $\mathrm{Cu} / \mathrm{Grf}$ (no treatment)

5. Maximum TC obtained from Set $\mathrm{C}\left(630 \mathrm{~W} \cdot \mathrm{m}^{-1} \cdot \mathrm{K}^{-1}\right)$ is 1.6 time higher than Cu matrix obtained by powder metallurgy process $\left(380 \mathrm{~W} \cdot \mathrm{m}^{-1} \cdot \mathrm{K}^{-1}\right)$ 
Erreur! Source du renvoi introuvable. shows the evolution of the in-plane and out-of-plane TC for the Set C composite material. The anisotropy of TC values of the Cu/Grf composite materials is fully induced by the Grf TC anisotropy and the orientation of the Grf in-plane. Thereby, the TC out-of-plane decreased with the volume fraction of Grf increases, while inplane TC increased over the entire range of concentration even at low vol. \% of Grf (below 20 vol.\%). This was not the case in [1] where for low content of Grf (with similar particulate size, around $300 \mu \mathrm{m})$ the in-plane TC of $\mathrm{Cu} / \mathrm{Grf}$ composite was below $\mathrm{Cu} \mathrm{TC}$. The corresponding TC of this composite is $630 \mathrm{~W} \cdot \mathrm{m}^{-1} \cdot \mathrm{K}^{-1}$ which is close to $60 \%$ higher than pure $\mathrm{Cu}$.

\section{Conclusion}

$\mathrm{Cu} / \mathrm{Grf}$ composite materials with different volume fraction of Grf (from 0 to 40 vol.\%) have been fabricated via vacuum uniaxial hot-pressing process. Effect of powder processing methodology on C-lattice parameters, Grf quality (defects, oxygenated $\mathrm{sp}^{3}-\mathrm{C}$ ), final composite Oxygen content and TC has been investigated. Results could be summarized as-follow:

1) Reductive thermal treatment at $400^{\circ} \mathrm{C}$ on Grf improves crystallinity structure as verified by XRD and Raman spectroscopy measurements. Elimination of points defects scattering centers such as impurities, interstitials and surface oxygenated $\mathrm{sp}^{3}-\mathrm{C}$ is taking place during this treatment.

2) A comparison between three mixing processes shows that the RAM device is an efficient mixer for the fabrication of $\mathrm{Cu} / \mathrm{Grf}$ composite. It allows faster mixing and elimination of defects on Grf edges without powder oxidation. Hence, the decrease of oxygen content in the final composite leads to better relative density.

3) Excellent TC up to $630 \mathrm{~W} \cdot \mathrm{m}^{-1} \cdot \mathrm{K}^{-1}$ for $\mathrm{Cu} / 40$ vol.\% Grf was obtained with this process combining new PPM and densification via vacuum hot-pressing. Even though, the interface between $\mathrm{Cu}$ and Grf was not studied in this work, Cu/Grf composite demonstrates better TC than composites fabricated using carbide forming elements [14][15] or metal coating on graphite [16] [17]. 


\section{Acknowledgments}

The authors would like to thank Eric Lebraud, Dominique Denux, and Christine Labrugère of the Institut de Chimie de la Matière Condensée de Bordeaux for performing the XRD, TGA and XPS analyses, respectively.

Declarations of interest: none

Funding: This research did not receive any specific grant from funding from funding agencies in the public, commercial, or not-for-profit sectors.

\section{References}

[1] Firkowska I, Boden A, Boerner B, Reich S. The Origin of High Thermal Conductivity and Ultralow Thermal Expansion in Copper-Graphite Composites. Nano Lett 2015;15:474551. doi:10.1021/acs.nanolett.5b01664.

[2] Bagheri GA, Abachi P, Purazrang K, Rostami A. Production of Cu-TiC Nanocomposite Using Mechanical Alloying Route. Adv Mater Res 2013;829:572-6. doi:10.4028/www.scientific.net/AMR.829.572. 
[3] Wang J, Zhang R, Xu J, Wu C, Chen P. Effect of the content of ball-milled expanded graphite on the bending and tribological properties of copper-graphite composites. Mater Des 2013;47:667-71. doi:10.1016/j.matdes.2013.01.008.

[4] Kováčik J, Emmer, Bielek J. Thermal conductivity of Cu-graphite composites. Int J Therm Sci 2015;90:268-302. doi:10.1016/j.jjthermalsci.2014.12.017.

[5] Liu B, Zhang D, Li X, He Z, Guo X, Liu Z, et al. Effect of graphite flakes particle sizes on the microstructure and properties of graphite flakes/copper composites. J Alloys Compd 2018;766:382-90. doi:10.1016/j.jallcom.2018.06.129.

[6] Pimenta MA, Dresselhaus G, Dresselhaus MS, Cançado LG, Jorio A, Saito R. Studying disorder in graphite-based systems by Raman spectroscopy. Phys Chem Chem Phys 2007;9:1276-91. doi:10.1039/b613962k.

[7] Sun Y, Zhang C, Liu B, Meng Q, Ma S, Dai W. Reduced Graphene Oxide Reinforced 7075 Al Matrix Composites: Powder Synthesis and Mechanical Properties. Metals (Basel) 2017;7:499. doi:10.3390/met7110499.

[8] Majumdar D, Baugh N, Bhattacharya SK. Ultrasound assisted formation of reduced graphene oxide-copper (II) oxide nanocomposite for energy storage applications. Colloids Surfaces A Physicochem Eng Asp 2017;512:158-70. doi:10.1016/j.colsurfa.2016.10.010.

[9] Jakani S. Effet des impuretés sur les mécanismes de recristallisation du cuivre tréfilé. Thesis, Université Sud Paris- Paris XI: 2004.

[10] P. M. Adams, H. A. Katzman, G. S. Rellick, and G. W. Stupian. Characterization of high thermal conductivity carbon fibers and a self-reinforced graphite panel. Carbon N Y 1998;36:233-45.

[11] Mellmann J. The transverse motion of solids in rotating cylinders-forms of motion and transition behavior. Powder Technol 2001;118:251-70. doi:10.1016/S00325910(00)00402-2.

[12] Tanaka R, Takahashi N, Nakamura Y, Hattori Y, Ashizawa K, Otsuka M. Verification of the mixing processes of the active pharmaceutical ingredient, excipient and lubricant in 
a pharmaceutical formulation using a resonant acoustic mixing technology. RSC Adv 2016;6:87049-57. doi:10.1039/c6ra16209f.

[13] Ferrari AC. Raman spectroscopy of graphene and graphite: Disorder, electron-phonon coupling, doping and nonadiabatic effects. Solid State Commun 2007;143:47-57. doi:10.1016/j.ssc.2007.03.052.

[14] Zhang R, He X, Chen Z, Qu X. Influence of Ti content on the microstructure and properties of graphite flake/Cu-Ti composites fabricated by vacuum hot pressing. Vacuum 2017;141:265-71. doi:10.1016/j.vacuum.2017.04.026.

[15] Ren S, Chen J, He X, Qu X. Effect of matrix-alloying-element chromium on the microstructure and properties of graphite flakes/copper composites fabricated by hot pressing sintering. vol. 127. Elsevier B.V.; 2018. doi:10.1016/j.carbon.2017.11.033.

[16] Chen J, Ren S, He X, Qu X. Properties and microstructure of nickel-coated graphite flakes/copper composites fabricated by spark plasma sintering. Carbon $N$ Y 2017;121:25-34. doi:10.1016/j.carbon.2017.05.082.

[17] Liu Q, He XB, Ren S Bin, Zhang C, Ting-Ting L, Qu XH. Thermophysical properties and microstructure of graphite flake/copper composites processed by electroless copper coating. J Alloys Compd 2014;587:255-9. doi:10.1016/j.jallcom.2013.09.207.

\section{Figures}



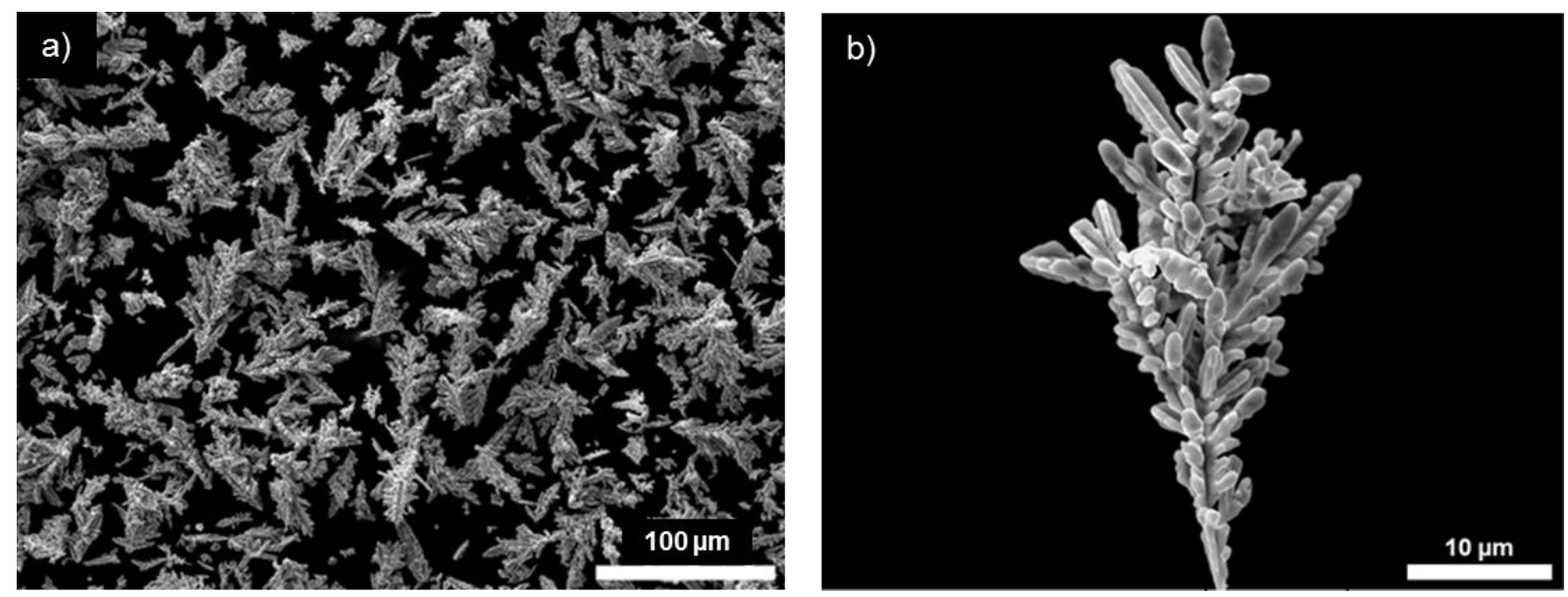

Figure 1. SEM micrographs of dendritic Cu powder.
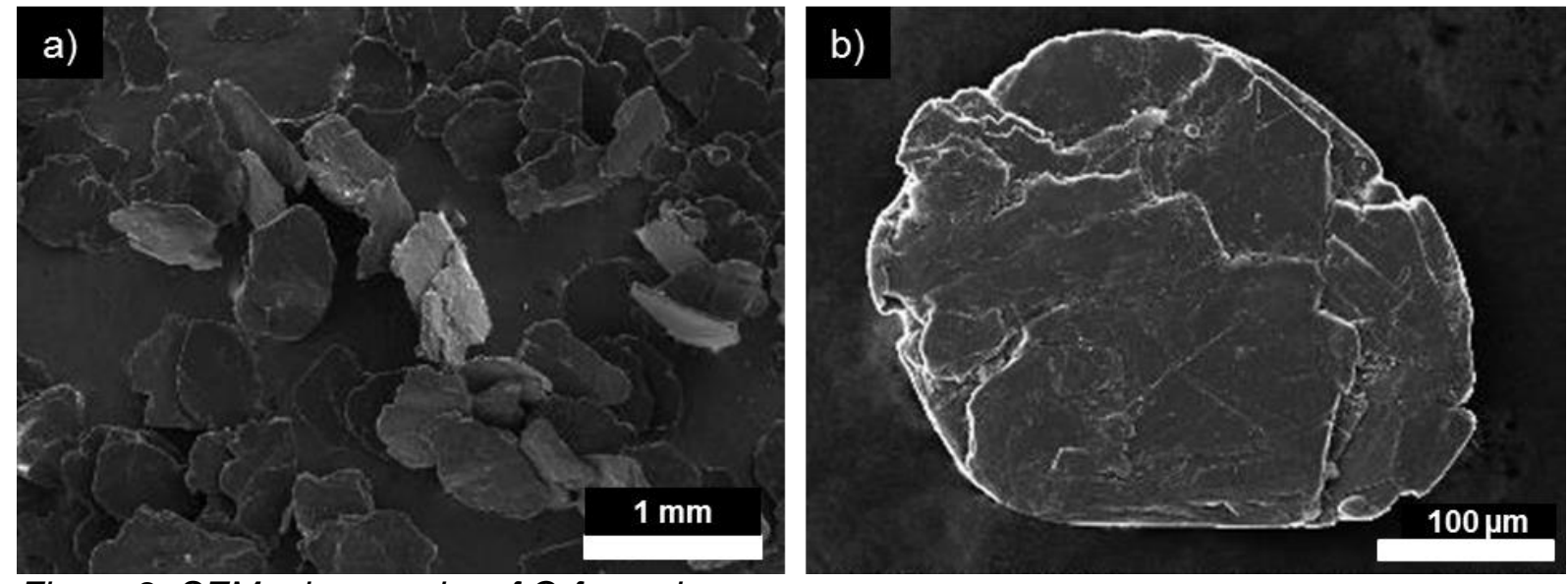

Figure 2. SEM micrographs of Grf powder. 


\section{Out-of-plane}

a)

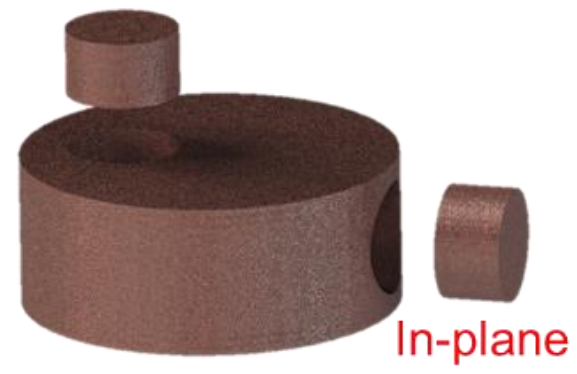

b)

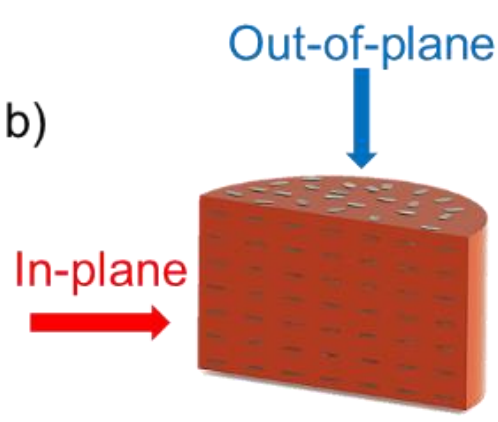

Figure 3. Definition of in-plane and out-of-plane directions in bulk Cu/Grf composite material. a) CAO model of unpolished samples $(\varnothing 6 \times 3.5 \mathrm{~mm})$ obtained after machining dense Cu/Grf composite material $(\varnothing 20 \times 8 \mathrm{~mm})$. b) CAO model of a Cu/Grf sample cut in the middle and polished revealing out of plane and in-plane directions of Grf.

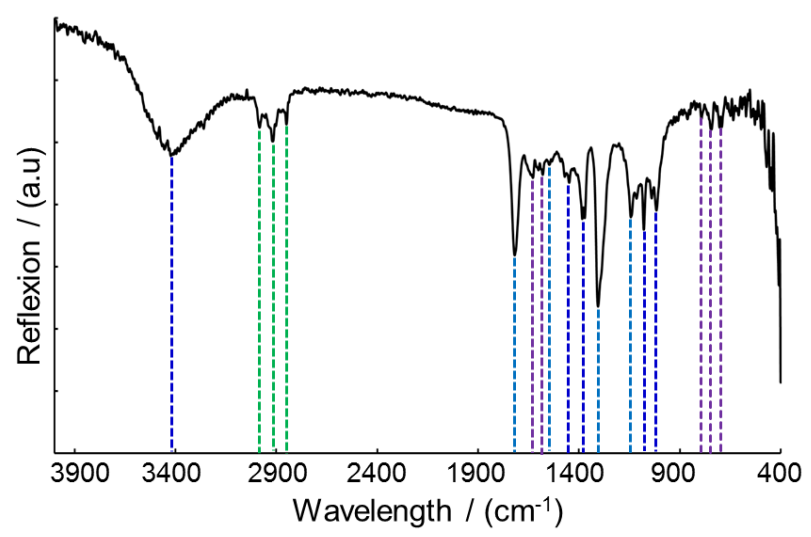

Figure 4. FTIR spectrum of as-received Grf. Dark blue lines correspond to peaks positions in wavelength $\left(\mathrm{cm}^{-1}\right)$ related to $-\mathrm{OH}$ stretching and bending vibrations. Purple lines: positions of stretching and bending of aromatic rings. Light blue lines: positions of epoxy, carbonyl and carboxyl groups. Green lines: positions of $\mathrm{CH}$ symmetric and asymmetrical vibrations of methyl and methylene. 


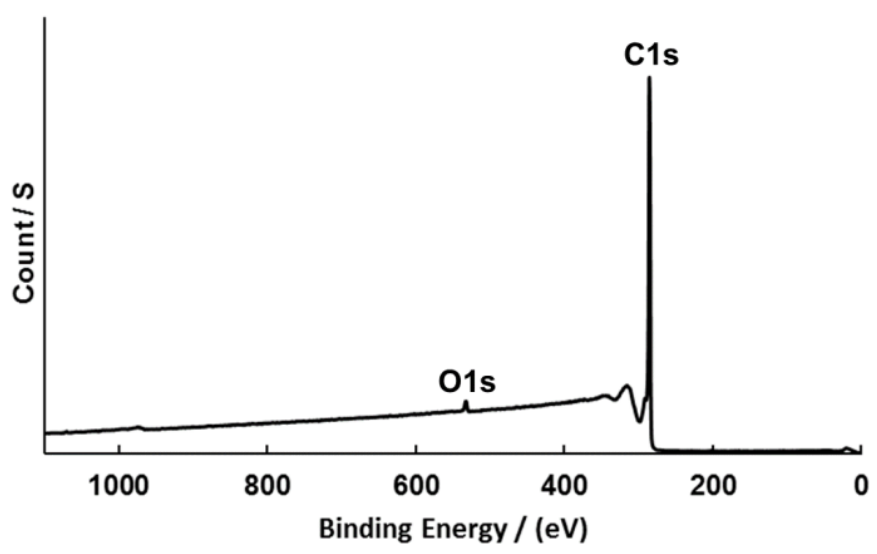

Figure 5. XPS Survey spectrum of as-received Grf.

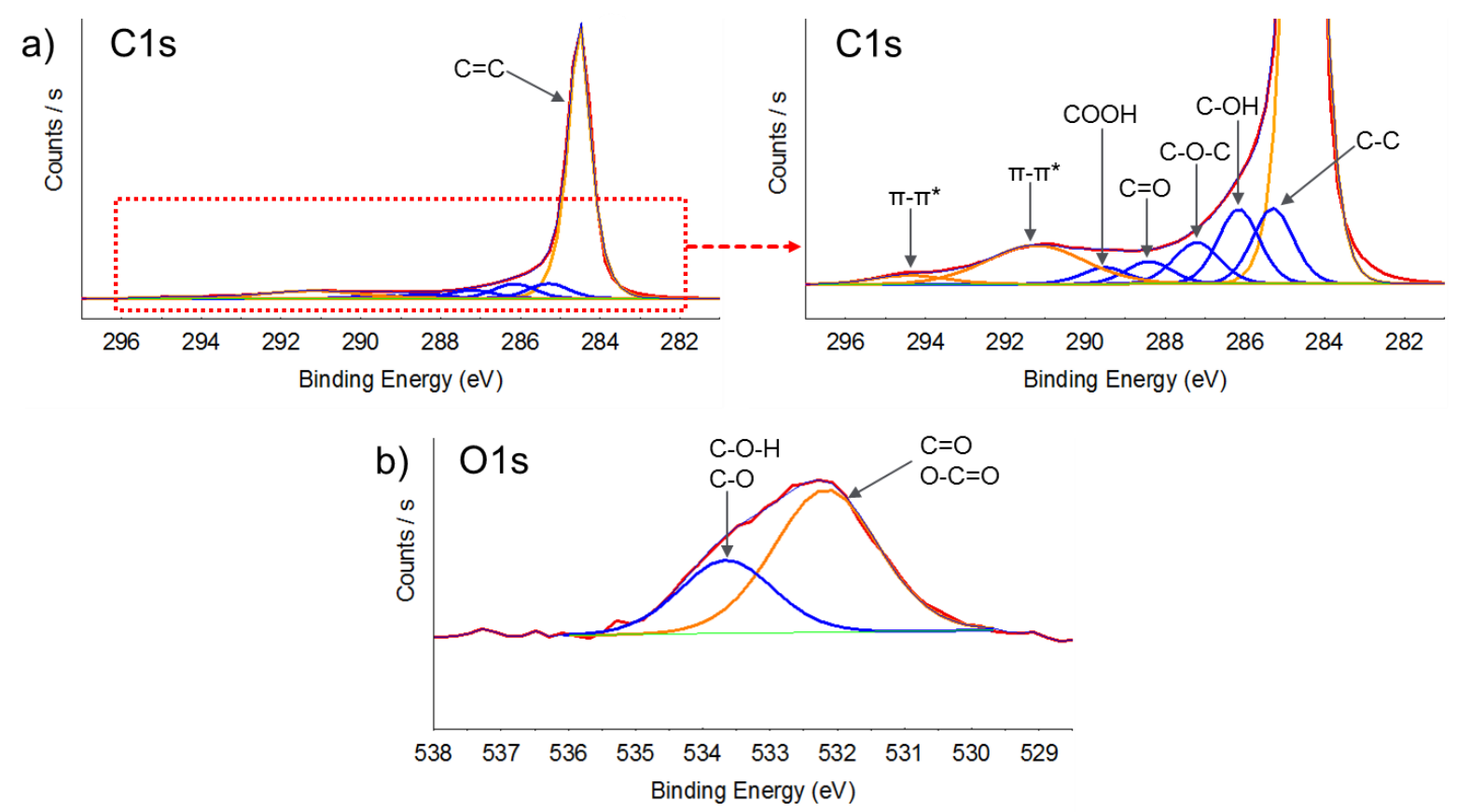

Figure 6. High resolution core level of a) C1s and b) O1s XPS of as-received Grf. 

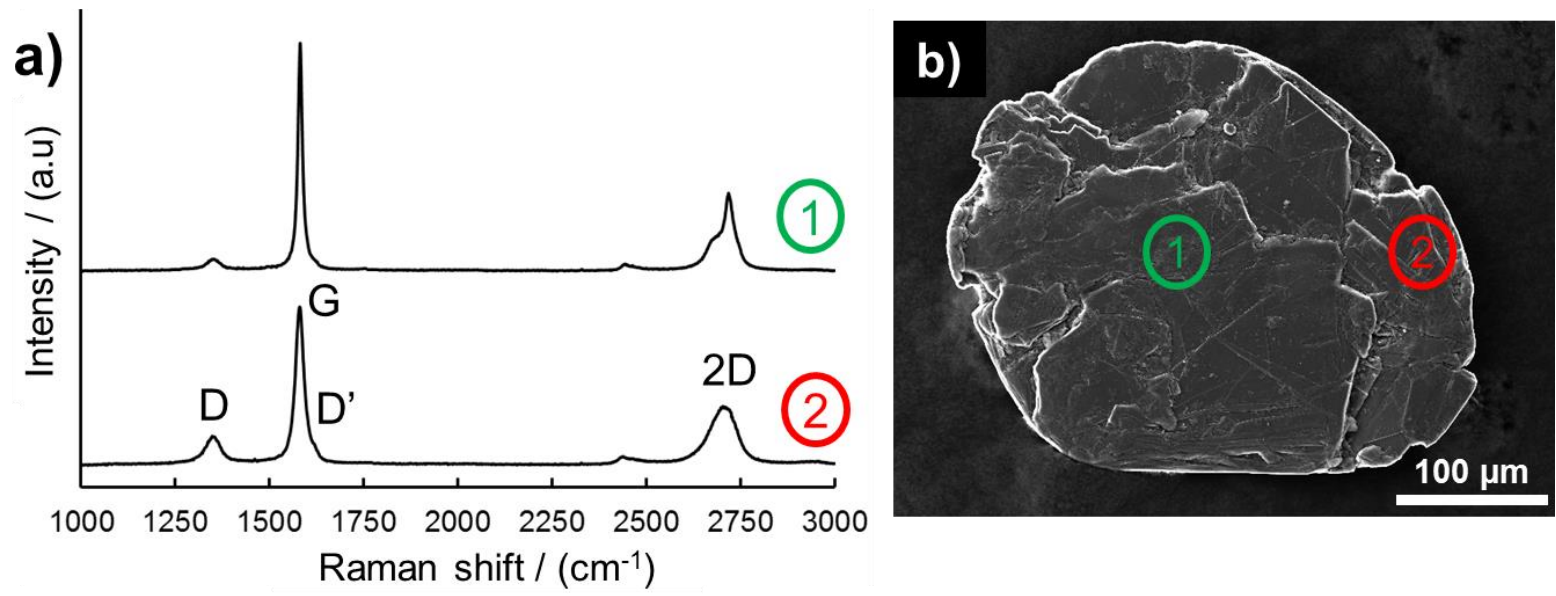

Figure 7. Raman spectra from Grf center a)1 \& edge a)2. The micrograph b) shows analysis locations on Grf.

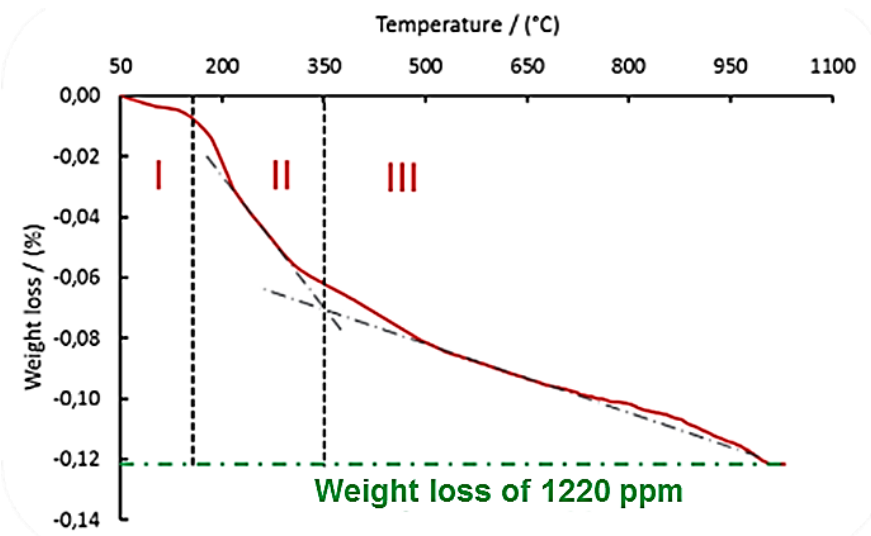

Figure 8. TGA analysis of Grf under $\mathrm{Ar} / \mathrm{H}_{2}(5 \%)$ reductive atmosphere. Evolution of the weight loss of Grf during elevation of temperature (from $50{ }^{\circ} \mathrm{C}$ to $1000^{\circ} \mathrm{C}$ ). 


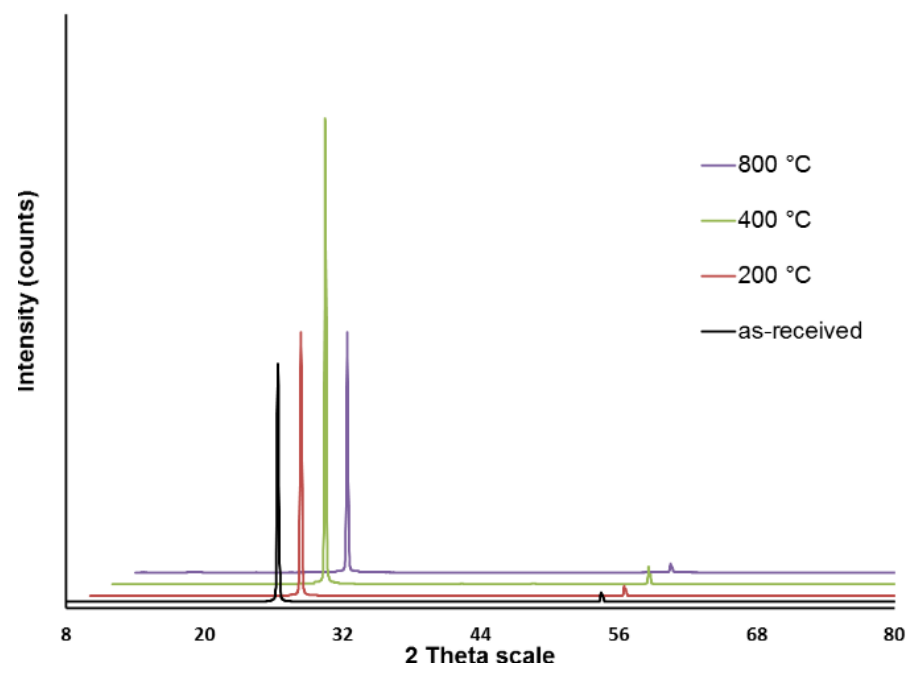

Figure 9. Representative X-Ray Diffraction patterns of Grf obtained after reductive treatment under $\mathrm{Ar} / \mathrm{H}_{2}(5 \%)$ at different bearing temperatures. (Peaks between different reductive treatments were shifted in both $x$ and $z$ for easier interpretation).

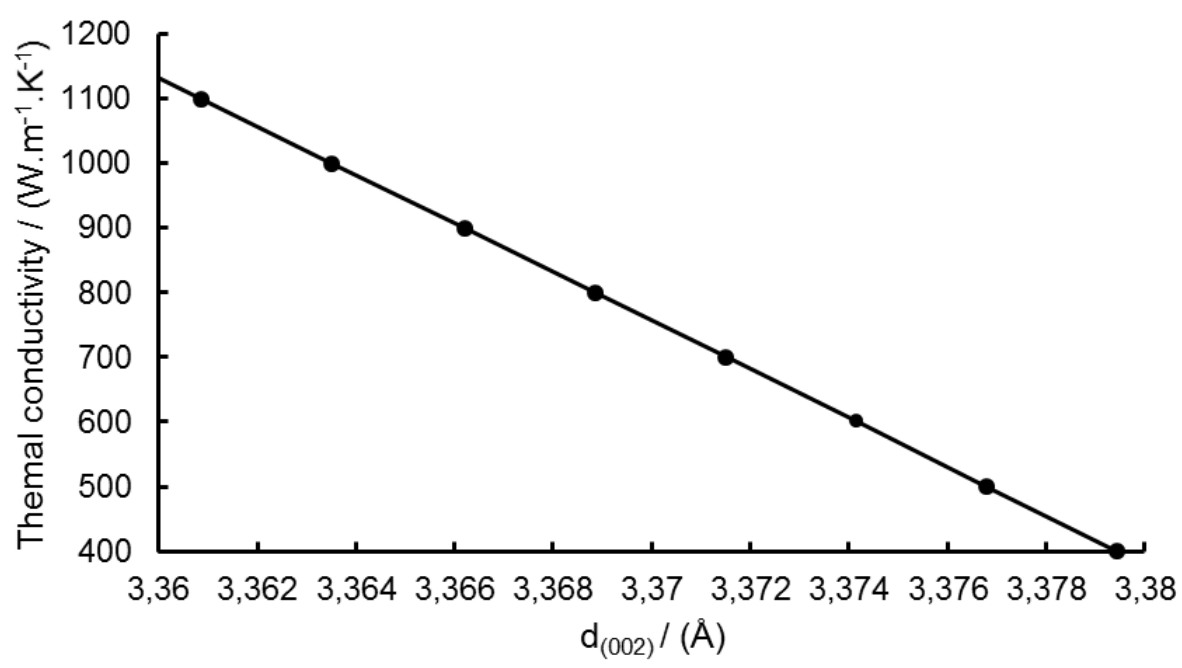

Figure 10. Thermal conductivity vs $d_{(002)}$ of Carbon fibers and ThermalGraph ${ }^{\circledR}$ panel. Adapted from [10]. 


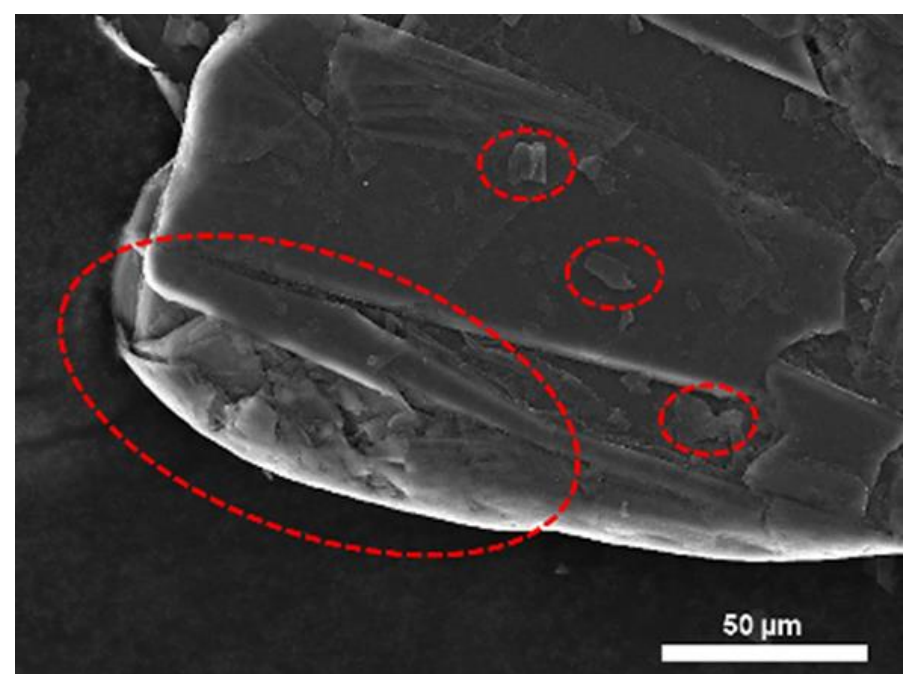

Figure 11. Point defects (surrounded in red) corresponding to folded edges and broken parts of Grf.
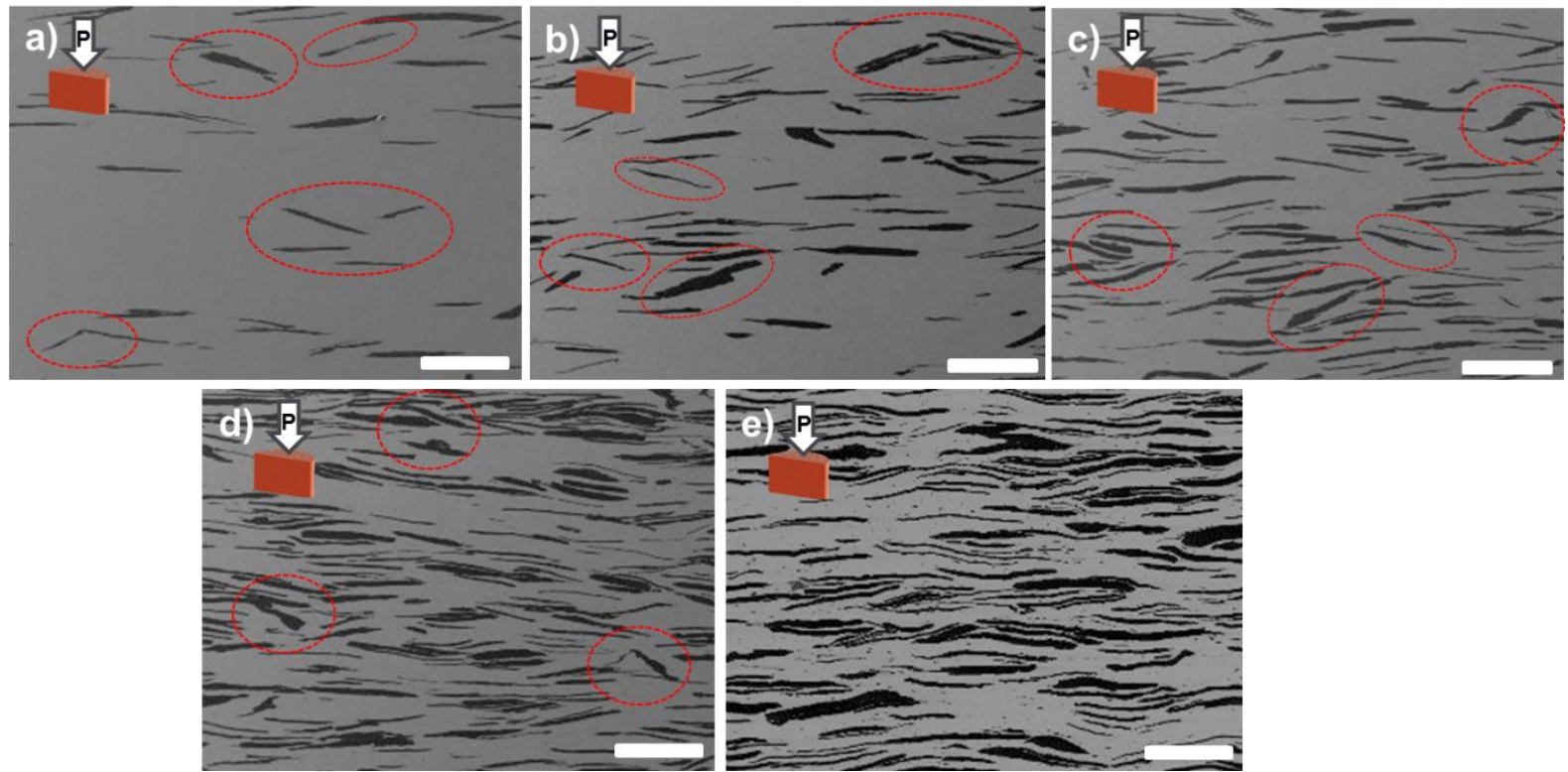

Figure 12. SEM micrographs of in-plane CU/Grf composites with a) 5, b) 10, c) 20, d) 30 and e) 40 vol. \% of Grf. Red circles represent location of misorientations of Grf in Cu matrix. Scale bars correspond to $500 \mu \mathrm{m}$. 


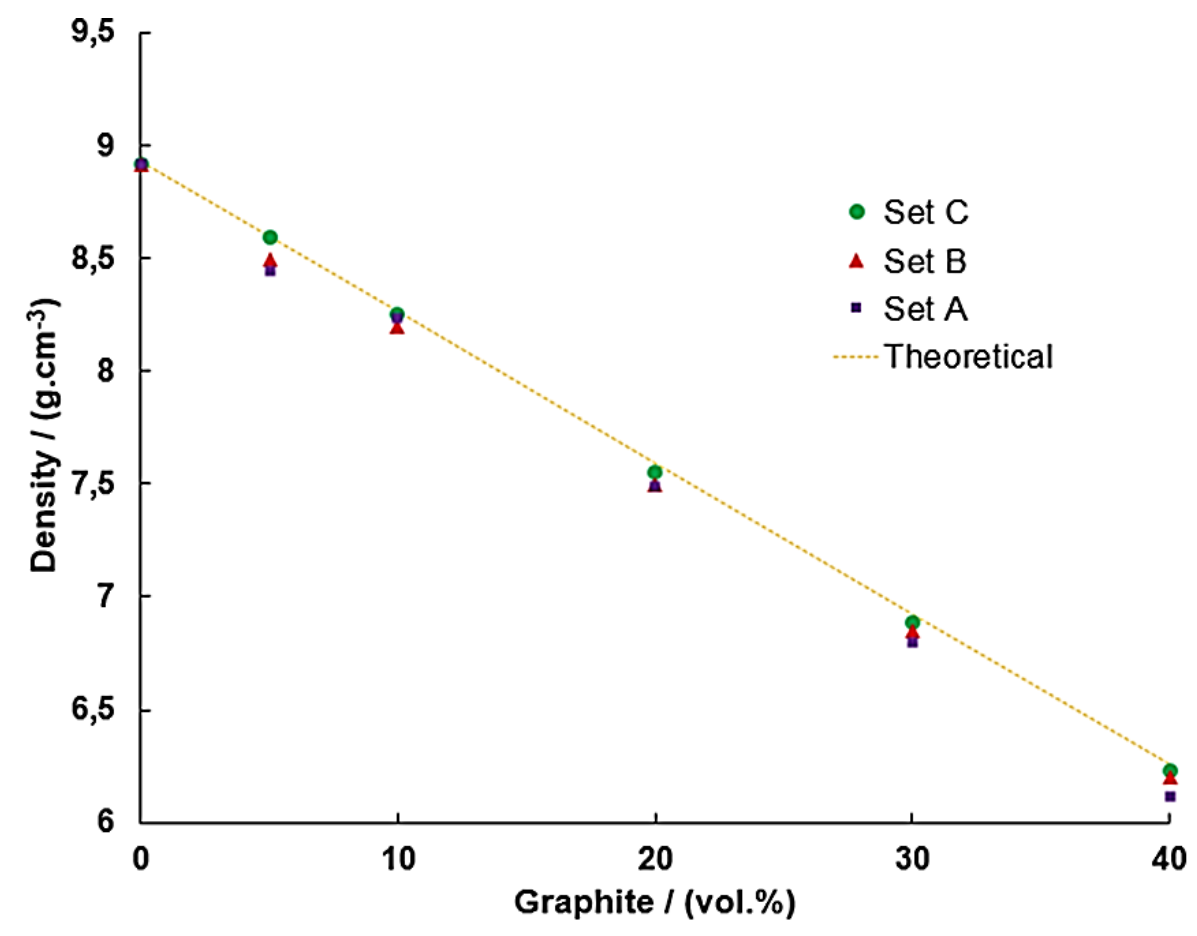

Figure 13. Plot of the density of the Cu/vol.\% Grf composites for the different sets used, in comparison with the theoretical (expected) density obtained by the rule of mixture.

\section{$\mathrm{Cu} / 40$ vol. \% Grf}

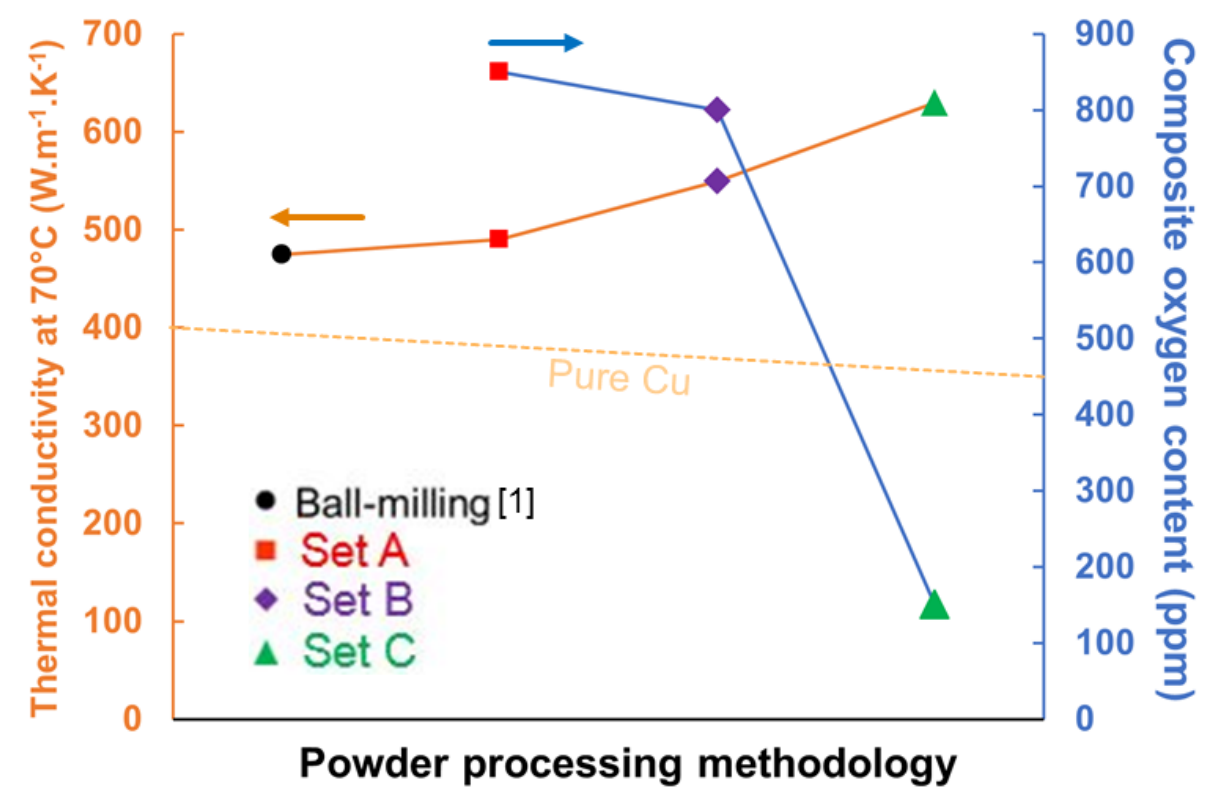

Figure 14. Effect of powder processing methodology on Cu/40 vol.\% Grf composite oxygen content and TC perpendicular to the compressive axis at $70^{\circ} \mathrm{C}[1]$. 


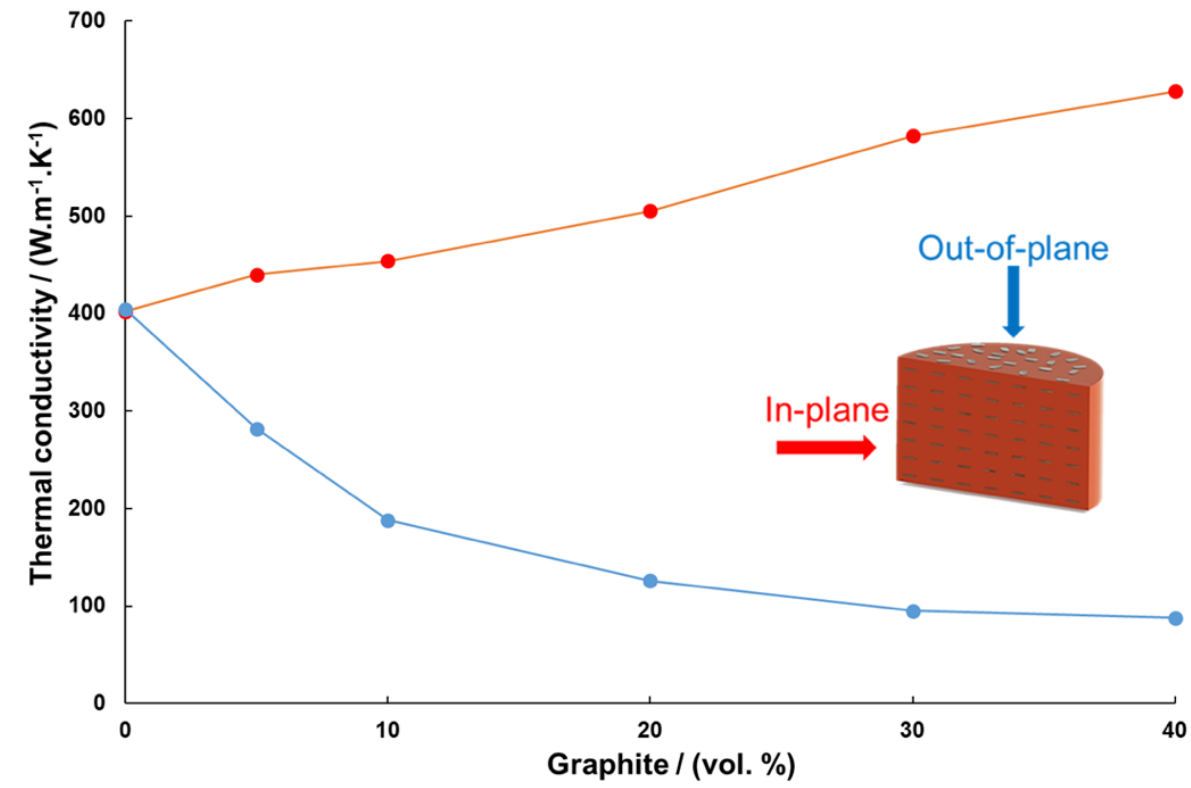

Figure 15. Thermal conductivity of Cu/Grf composite materials with volume fraction of Grf dependence. In-plane TC is represented by the red line and out-of-plane TC by the blue line. 


\section{Tables}

Table 1. XPS qualitative analysis of Grf.

\begin{tabular}{lllllllllll}
\hline At. \% C & & & & & & & At. \% O & $\begin{array}{l}\text { At. } \\
\% \mathrm{Cl}\end{array}$ & $\begin{array}{l}\text { At. } \\
\% \mathrm{~S}\end{array}$ \\
\hline $\mathrm{Sp}-\mathrm{C}$ & $\mathrm{C}-\mathrm{OH}$ & $\mathrm{C}-\mathrm{O}-\mathrm{C}$ & $\mathrm{C}=\mathrm{O}$ & $\mathrm{H}-\mathrm{O}-\mathrm{C}=\mathrm{O}$ & $\pi^{2}-\pi^{*}$ & Total & & & \\
\hline 70.6 & 5.4 & 6.2 & 3.7 & 3.8 & 8.7 & 98.4 & 1.4 & 0.1 & 0.1 \\
\hline
\end{tabular}

Table 2. XRD parameters of Grf before and after reductive treatment at different bearing temperatures.

\begin{tabular}{lllll}
\hline $\begin{array}{l}\text { Temperature of } \\
\text { reduction }\left({ }^{\circ} \mathbf{C}\right)\end{array}$ & $(\mathrm{hkl})$ & $\mathrm{d}(\AA)$ & $\mathrm{FWHM}\left({ }^{\circ}\right)$ & $\begin{array}{l}\text { Grf Kc obtained from }[10] \\
\left(\mathrm{W} \cdot \mathrm{m}^{-1} \cdot \mathrm{K}^{-1}\right)\end{array}$ \\
\hline Single crystal & $(004)$ & 1.678 & - & 1600 \\
& $(002)$ & 3.356 & & \\
As-received Grf & $(004)$ & 1.682 & - & 500 \\
& $(002)$ & 3.377 & 0.178 & \\
200 & $(004)$ & 1.682 & - & 500 \\
& $(002)$ & 3.377 & 0.173 & \\
400 & $(004)$ & 1.679 & - & 1130 \\
& $(002)$ & 3.360 & 0.132 & \\
800 & $(004)$ & 1.682 & - & 6 \\
\hline
\end{tabular}


Table 3. Integrated intensity ratio $A_{D} / A_{G}$ and average $G$ and $2 D$ peak positions of Grf after reduction under $\mathrm{Ar} / \mathrm{H}_{2}(5 \%)$.

\begin{tabular}{ccccccc}
\hline $\begin{array}{c}\text { Temperature of } \\
\text { reduction }\left({ }^{\circ} \mathrm{C}\right)\end{array}$ & $\mathrm{A}_{\mathrm{D}} / \mathrm{A}_{\mathrm{G}}$ & $\begin{array}{c}\text { Center } \\
\mathrm{w}_{\mathrm{G}}\left(\mathrm{cm}^{-1}\right)\end{array}$ & $\mathrm{w}_{2 \mathrm{D}}\left(\mathrm{cm}^{-1}\right)$ & $\mathrm{A}_{\mathrm{D}} / \mathrm{A}_{\mathrm{G}}$ & $\mathrm{w}_{\mathrm{G}}\left(\mathrm{cm}^{-1}\right)$ & $\mathrm{w}_{2 \mathrm{D}}\left(\mathrm{cm}^{-1}\right)$ \\
\hline As-received Grf & $0,13( \pm 0,04)$ & 1578 & 2718 & $0,36( \pm 0,05)$ & 1579 & 2721 \\
200 & $0,14( \pm 0,03)$ & 1580 & 2719 & $0,12( \pm 0,02)$ & 1580 & 2721 \\
400 & $0,05( \pm 0,01)$ & 1580 & 2720 & $0,11( \pm 0,02)$ & 1580 & 2720 \\
800 & $0,10( \pm 0,02)$ & 1579 & 2719 & $0,13( \pm 0,02)$ & 1578 & 2716 \\
\hline
\end{tabular}

Table 4. Calculated integrated intensity ratio $A_{D} / A_{G}$ and average $G$ and $2 D$ peak positions of Grf after different type of mixing.

\begin{tabular}{ccccccc}
\hline \multirow{2}{*}{ Type of mixing } & $\mathrm{A}_{\mathrm{D}} / \mathrm{A}_{\mathrm{G}}$ & $\mathrm{w}_{\mathrm{G}}\left(\mathrm{cm}^{-1}\right)$ & $\mathrm{w}_{2 \mathrm{D}}\left(\mathrm{cm}^{-1}\right)$ & $\mathrm{A}_{\mathrm{D}} / \mathrm{A}_{\mathrm{G}}$ & $\mathrm{w}_{\mathrm{G}}\left(\mathrm{cm}^{-1}\right)$ & $\mathrm{w}_{2 \mathrm{D}}\left(\mathrm{cm}^{-1}\right)$ \\
\hline As-received Grf & $0.13_{( \pm 0.04)}$ & 1578 & 2718 & $0.36_{( \pm 0.05)}$ & 1579 & 2721 \\
3D & $0.1\left(_{( \pm 0.04)}\right.$ & 1579 & 2718 & $0.26_{( \pm 0.02)}$ & 1578 & 2721 \\
Resonant Acoustic & $0.12_{( \pm 0.03)}$ & 1579 & 2718 & $0.20{ }_{( \pm 0.03)}$ & 1577 & 2717 \\
\hline
\end{tabular}

